\title{
تجديد النحو فى تعليم اللغة العربية عند إبراهيم مصطفى
}

\author{
M Zikri
}

Institut Agama Islam Negeri Bengkulu, Indonesia

mzikri@iainbengkulu.ac.id

\begin{abstract}
The existence of Nahwu's knowledge among other disciplines-Kalam Science, Fiqh, Tasawuf, Tafsir, and Hadith-is one of the traditional knowledge of Arabic (al-'um an-naqliyyah) which still has a significant contribution in Islamic studies. Ibn Khaldun in his al-Muqaddimah viewed the nahwu knowledge as an integral part that can not be separated in the progress of traditional sciences (al-'umul an-naqliyyah), because of the success and truth of the study of the origin of the sciences (al-'ulum an- naqliyyah). The Middle East with a wealth of knowledge and knowledge, especially in linguistics, has produced many thinkers and linguists, especially in the development of Arabic language science. Introducing the figure of a linguist reformist in the modern era, Ibrahim Musthafa.
\end{abstract}

Keywords: Nahwu, Reformist, Linguist

$$
\begin{aligned}
& \text { جزء لايتجزأ من علوم اللسان العربى } \\
& \text { التى تتكون من أربعة فروع وهى علم } \\
& \text { اللغو وعلم النحو وعلم البيان وعلم }
\end{aligned}
$$

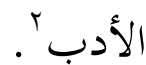

$$
\begin{aligned}
& \text { ونعلم على وجه اليقين أنّ من } \\
& \text { ناحية التاريخية لعلوم النحو ذكر أنّ } \\
& \text { الأسباب التى ألّف علم النحو في أوّل } \\
& \text { نشأته هو ظهور اللحن بف البحتمع }
\end{aligned}
$$

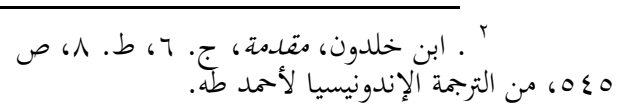

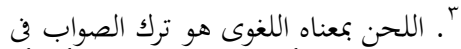

$$
\begin{aligned}
& \text { القراءة والنشيد ونخو ذلك. وألحن الرجل في كلامه ألى أخطأ }
\end{aligned}
$$

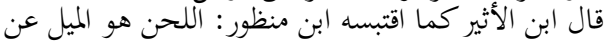

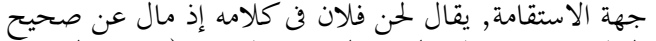

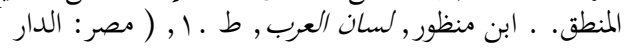

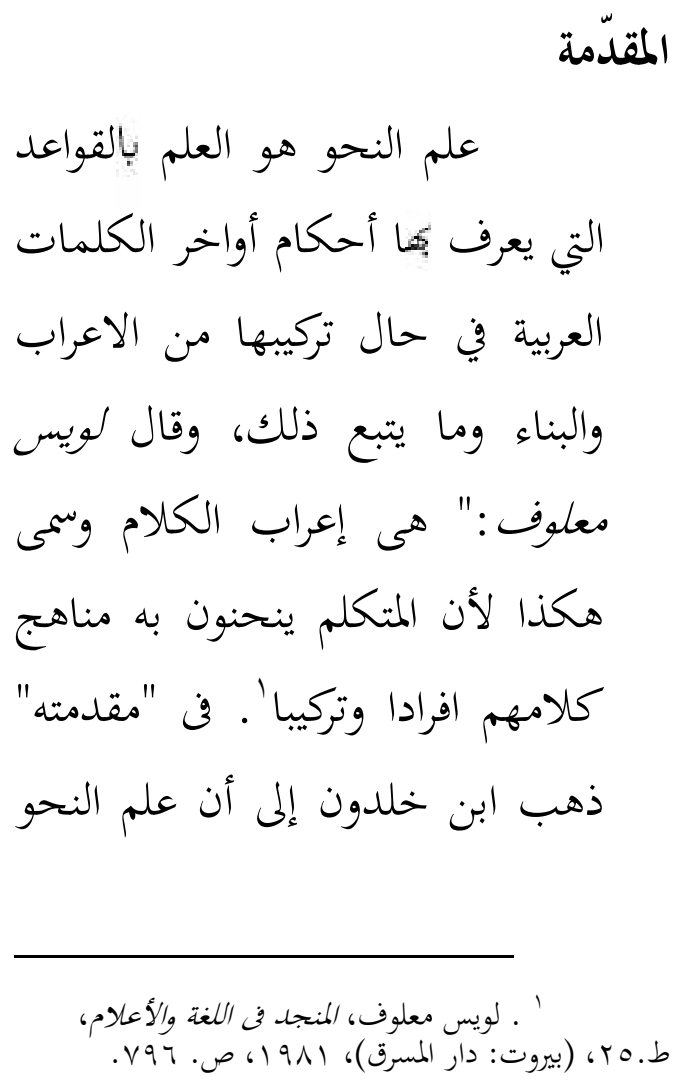


علي بن أبي طالب يُدئ، واختلفو في سبب ذلك، قال القفطي في لإانباه :

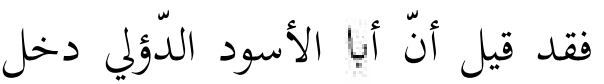

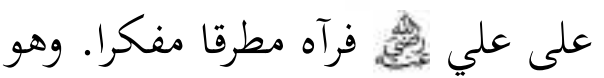
كذلك واضع النقاط في أحرف القرآن ولإعراب الذى ينقسم إلى ثلاثة أقسام

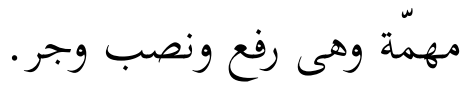
ورجال النحاة الأخرون الذين

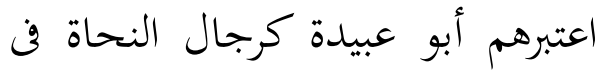

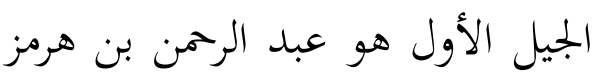

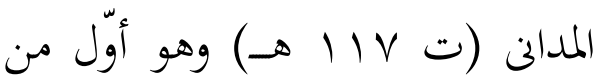
يعلم النحو في المدينة وكان تلميذ الدوّلى, ميمون الأقرن, عنبسى ابن الملنية وكان تلهيذ معدن الفيل, وعبد الله ابنأبي إسحاق النيس انق الحضرامى (ت IVV هـ), سيبويه (مؤلف "الكتاب") وهو من تلميذ الكاتب ابن أحمد, حمدون النحو التور

$$
\text { (النحاة من أفريقا). }
$$

George Abraham Makdisi, Cita . (Jakarta : 1., Cetء Humanisme Islam, bab $. \curlywedge \wedge \vee-\mid \wedge \uparrow$, hlm. ץ... Serambi),
العرى و لقد نشأ علم النحو العربي بسبب الزيغ أو شبه الإخراف الطارئ

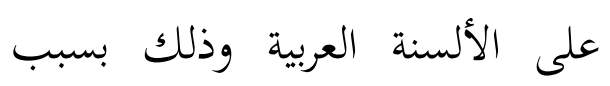

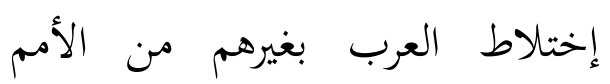

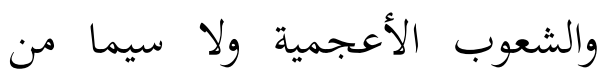
الأقطار البجاورة للجزيرة العربية وخاصة أن الدّين الإسلامي جاء لبطاء بطبعه متفتحا على الشعوب والحظارات والأمم وداعيا إلى الدخول فيه وهو ما إنعكس سلبا وللأسف على اللسان العربي وجعل الفصاحة تتلاشى. فالذى نخاله قريبا إلى الواقع الع القان

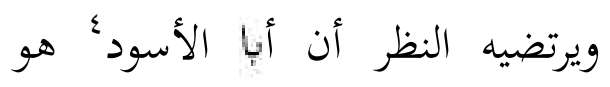

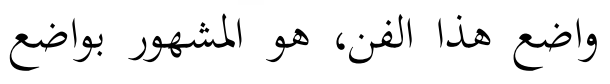
لعلم النحو، بأمر من أمير المؤمنين هوني

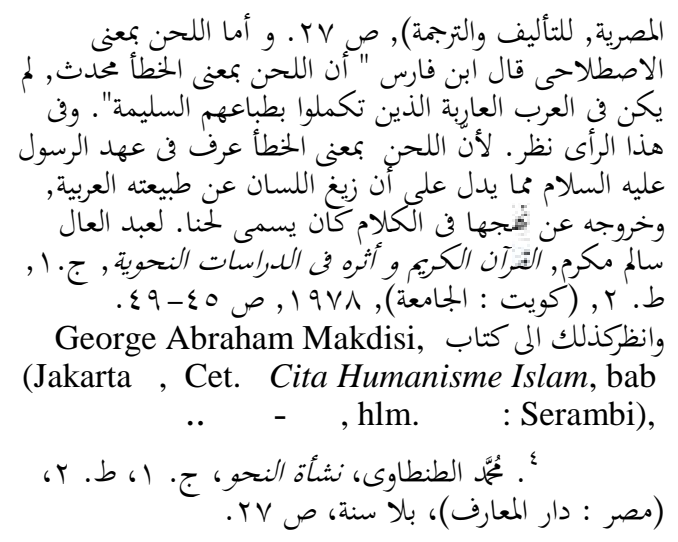


القدامى من النحويين : استقروا

النصوص ووضعوا القاعدة. لقد اعتمد

الخليل بانى صرح النحو، على نبعين : النقل عن القراء أى قراء القرآن الكريم

قالأخذ عن أفواه العرب الخلص^.

التعليل هو ايجاد التى تسبب

الإعراب. إن اللغة العربية لغة معربة

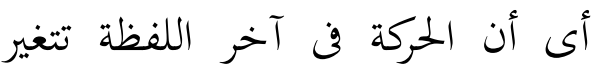

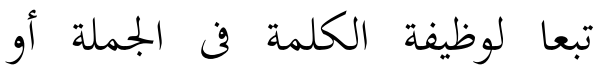

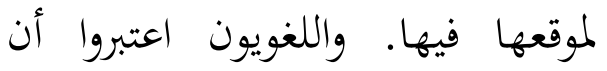

الكلمة ساكنة قبل التركيب مثل

(ولد) ولكن تصبح (ولد-ولدا-ولد)

في التركيب بفضل عامل. فالعامل هو الونا

الذى يسبب الرفع والنصب والجزم

والجر. ومرد كل خلاف في النحو إلى الى الى

$$
\text { العامل ةتقديرهُ . }
$$

القياس هو حمل غير المنقول

أى الكلام الذى لم يرد في نص قديم

على المنقول أى الكلام الذى ورد فن الفي

$$
\begin{aligned}
& \text { ^ . أنيس فريخة، نظرإت في اللغة، ط. ب، (بيروت }
\end{aligned}
$$

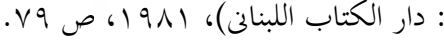

$$
\begin{aligned}
& \text { " . نفس المصدر, ص •. }
\end{aligned}
$$

اعتمد الخليل في تأصيله

لقواعد النحو و وإقامة بنيانه على لقالى

السماع والتعليل و القياس" لـ

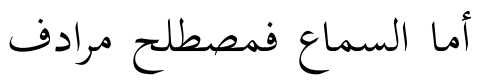

للاحتجاج فن اللغة. والبيان لذلك أنه

إذا أردنا أن ندرس لهجة لم توضع لها

قواعد من قبل, فيتوجب علينا أن

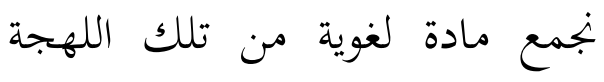

لنستبط أحكامها وقواعدها بناء على ملى ادها

ما نلاحظه من مظاهر لغوية. فإذا

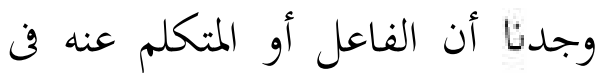

الجملة يرد دوما بحالة الرفع مثل قام المان

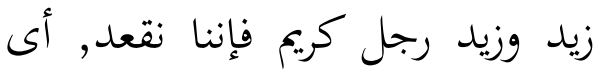

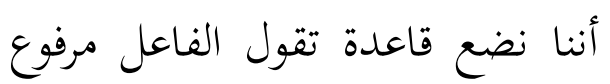

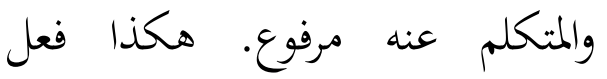

• هو الخليل بن أحمد الفراهيدى، عربى من ونمان.

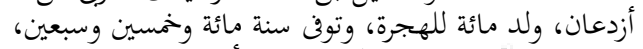

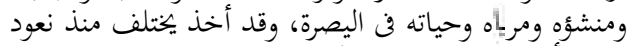

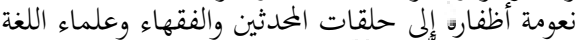

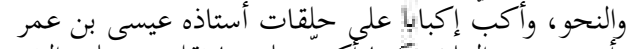

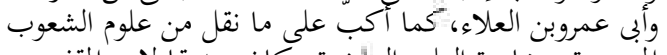

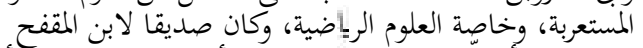

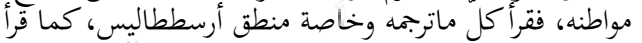

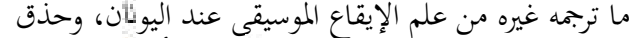

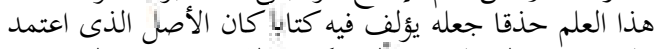

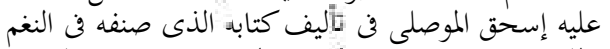

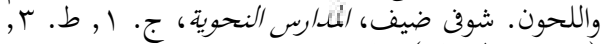

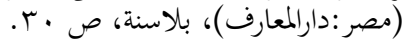

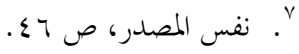


النحو لأول مرة لإصلاح النطق في الكلام أى خروجه من اللحن حتى لإحلى النقا تسابق العلماء فن تأليفه. واذا كنا تأملنا القضية النحوية المعاصرة وجدنا أن الطلاب قد شعروا بأن النحو النحا صعبة، وهذه القضية أصابتها الطلبة في الجامعات والمدارس والمعاهد حتى يجتاجوا إلى طول الوقت فقط لتعميق هذا العلم مع أن النحو والصرف لوف لعط لعدف كوسيلة لنيل المعارف الأخرى. وقد العد العرقد ظهر بنا أن النحو ليس نظرية تسلط

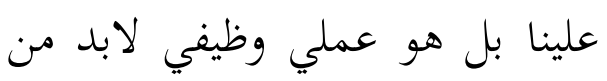

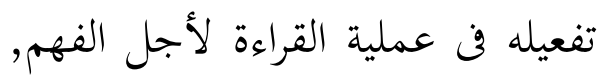
لا لأجل النحو ذاته.

وبهذا البحث سيحاول الباحث كشف آراء ابراهيم مصطفى في تجديد النحو فن كتابه "احياء النحو". وكان ابراهيم مصطفى هو

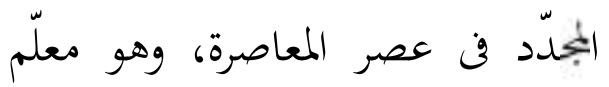
في كليّة الآدب بجامعة الأزهر فن

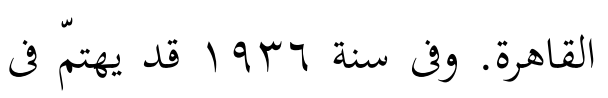

النصوص، وذلك لعلة جامعة بينهما

على المنقول في حكم لعلةجامعة' '.

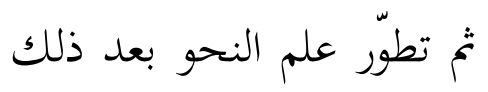
فنشأت مدارس نغوية وألفت كتب نطب بعد عظيمة تبين وتشرح وتفصل في اساليب العرب في الكلام ومعرفة اللغة الصحيحة من اللحن، ومن أشهر هذه المدارس ، المدرستان الكوفية

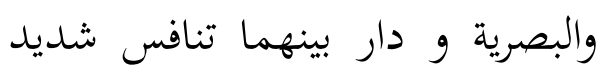
ومناظرات مشهورة لعل من أشهرها المناظرة المعروفة بين الكسائي وسيبويه وهي الشهيرة بالزبورية' . على الرغم من أن اللغويين

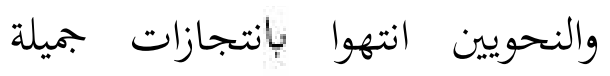
مشهورة في دعم صرح علم النحو فيتقبل باعجاب واحترام من الجهات الكثيرة, غير أن هناك انتقادات كثيرة لاتقل أهميتها في اصلاح النحو. اذا كنا تأملنا عن قضية كيفة النحا النحو وضع النحو الأول, أن وضع علم 
غير الدينى. أما البواعث الدينة هى: سبب شيوع اللحن على ألسنة الأعاجم والموالى, وكان قد لد أخذ فن الظهور منذ حياة

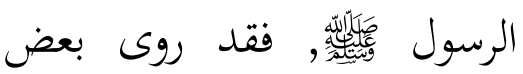

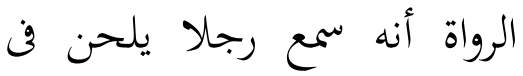
كلامه, فقال "أرشدوا أخاكم فإنه قد ضلّ". من هذه العبارة اعتقد الباحث أن اللحن قد هن هلد العبار ظهر في صدر الإسلام. وأما البواعث غير الدينية هى : أن

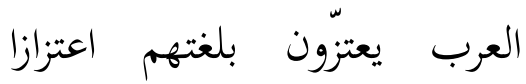

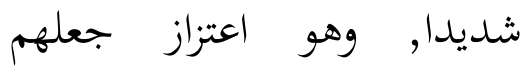
يخشون عليها من الفساد حين

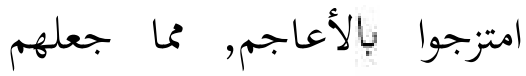
يجرصون على رسم أوضاعها خوفا من الفناء والذوبان فئ اللغات الأعجبية.

وقد اتفق معظم الروايات التاريحية أن أبا الأسود الدؤلي

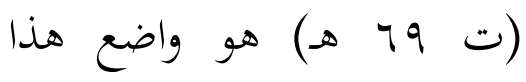

كتابة عن النحو يعنى "احياء النحو". وقال فن مقدمته "هذا بحث من

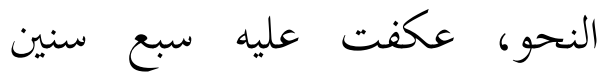
وأقدمه إلينا فة صفحات" 'T '. المباحث أ. نشأة وتطور النحو العربي ونشأة النحو العرى مرتبطة

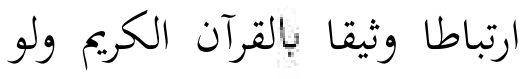

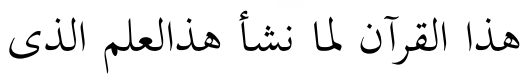
تمت له السيطرة فيما بعد على كل علم من علوم العربية وآدابها. ومن أهم الأسباب التى جعلت العربة وادلما. أولى الأمر من المسلمين وعلما الاسبا ئهم يفكرون فن وضع اللبنة الأولى فن صرح هذا العلم اللحن فن قراءة القرآن الكريم. وكان تاريخ واضعا للنحو

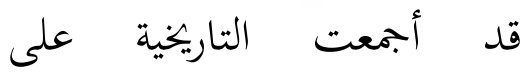
الأسباب واضع النحو أشهر إلى إنى بواعث مختلفة. منها الدينى ومنها

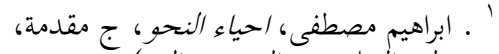

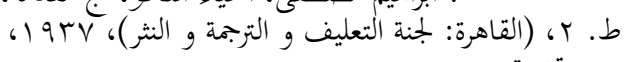


وتم كل ذلك بالبصرة التى سبقت إلى وضع قواعد العربية, وعلى هذا بدأ التفكير اللغوي عند العرببمعناه العلمى على أساس الوصفية, الذى يتمثل في جمع المادة وتصنيفها واستنباط القواعد وتحكيمها.

وفى البصرة كان الخليل بن أحمد (ت 170 هـ) الغاية في لن استخراج مسائل النحو ويصحيح القياس, وهو أول من استخرج علم العروض وعمل كتاب العين, أما سيبويه فهو صاحب أول مؤلف في النحو يصل إلينا. وكان ألف فن إحكام العربية وقواعدها

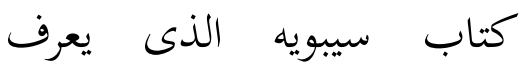
بـــالكتاب". وهو تام الصنعة في شموله وعمقة ودقة مصطلحه. وأصبح (كتاب سيبويه) أساسا لكل ماكتب بعده في لم علم
الفن, وهو أول إنسانا الذى يفكرون في شيوع اللحن على نص القرآن و اللغة. من ذلك يوضع النقط التى تدل على

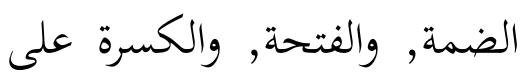
أواخر الكلمات. ولكن سكك ولك ولك الناس على أن أبا الأسد هو . ولعل أول الواضع لعلم النحو هو عبدالله بن أبى إسحاق مولى آل الحضرامى (ت ل هجرية) الذى يقول عنه ابن سلام بعد ذكره أبا الأسود "ثم

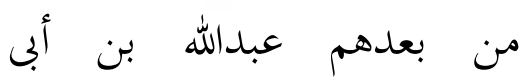
إسحاق مولى آل الحضرامى فكان أول من بعج النحو, ومد القياس والعلل, وأبو عمرو بن العلاء بقي بعده طويلا, وكان أبي إسحاق أشدّ تحريدا للقياس, بعده وأبو عمرو أوسع علما بكلام العرب. 
مضبوطة بالمعنى الذى أفاده

الضبط عند الكلام عن

خصائص العلم, ثم دراسة

مفردات متنها فيما وراء القوعد

دراسة إن اتسمت بلموضوعية

لارتباطها بما يفرضه الموضوع من

النتائج فهى لم ترق إلى مستوى

الصناعة, لأكما اعتمدت عاى

الإستقراء التام ووصلت إلى نتائج

لايمكن التحقيق بالمنهج العلمى

من صدقها ولم ترتبط بمبتدأ

الحمية ولا بالتقعيد, تلك هي

الدراسة التى نعرفها اليوم باسم

(فقه اللغة). و العوامل الثلاتة

التى أشرنا إليها منذ قليل هى :

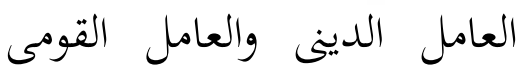

زالعامل السياسى.

ب.دعوة ابن مضاء في تجديد النحو

كان النحو العربى في القرن

الرابع الهجرى هجة بارتفاع

صوت ابن مضاء القرطبي(ت
ودراسة الخليل للأصوات

كانت نموذجا آخر لنظر العلمى

فقد رتب الأصول ترتيبا صوتيا

حسب الحير و والمخراج, كما

اعتمد عاى الجانب السمعى كما

يتمثل في وقع الصت على

الأذن, وصف حروف المد واللين

وذكر صفاتَا.

وبهذا استطاع الخليل

وسيبويه أن يقدما للعربية نموذجا

بنيويا لوصف العربية صوتيا

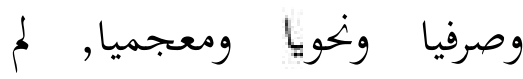

يستطع أحد أن ينال منه أو وصريكا

يقدمة بديلا عنه حتى قال

قائلهم: "من أراد أن يعمل كتابا

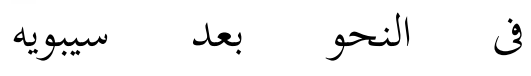

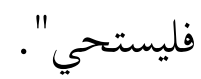

وربما ثلاثة العوامل المؤثرة

فن نشأة النحو, و الدافعة إلى

دراسة اللغة العربية دراسة منظمة

لاستخراج قواعدها, أي دراسة 
الحقيقى فن تغيير الإعراب هو

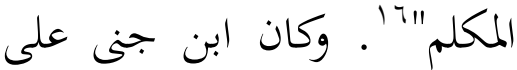

أن العامل اللفظى والمعنوي ليس لـ لـ

حقيقيا.

التصريح من ابن جنى

لايتوقف إلى عصره بل تدحرج

النظر باستمرار يجعله موسعا لئ

بذاته. فن بداية القرن الرابع

مذهبان في النحو يختلفان في

النظر , مذهب يعمل النحو على

تصميم المنطق والفقه وهو

مذهب قديم, وأراد بعضهم

لاستقلال النحو من تصميم

المنطق والفقه وهو مذب جديد.

يميل المذهب القديم إلى

فهم النحو على أنه جزء من

المنطق العقد, في المنطق مثلا

ارتباط " المقدمة" و "النتيجة" او

ارتباط "العلة" و "الحكم" في في

الفقه. والمشهور بداية هذا

\footnotetext{
'" . محيدين، آراء الكاتور شوقى ضيف حول

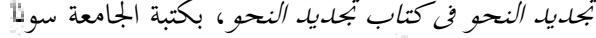

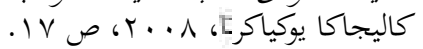

rهـ ( ) , ذلك الوقت

ليس له انتقاد قط بل يرده. وهو

يرى على أن النحو العربى نظره

لابد بتغيره كله. على الحقيقة,

آراء النحوية الجديدة التى بناها

ابن مضاء يبدأ من نظر

الزجاجى ع إبن

بالإستمرار, وهما نحاتان في القرن

الرابع الهجرى. كان رد ابن مضاء

على نظرية العامل في النحو

بتعليقه القصير "إن العامل

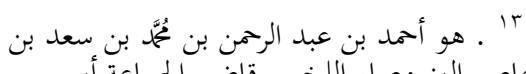

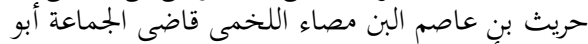

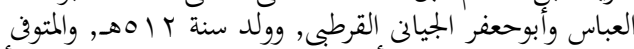

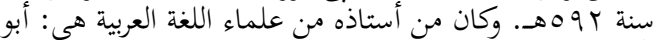

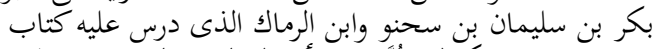

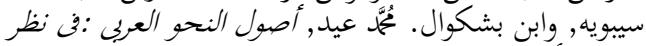

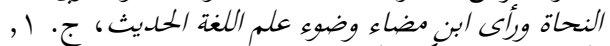

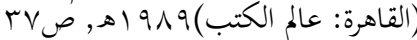

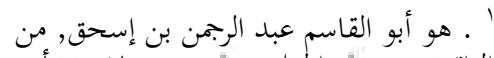

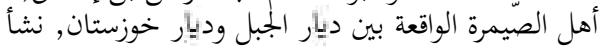

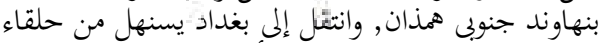

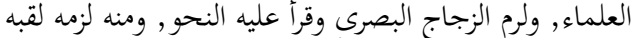

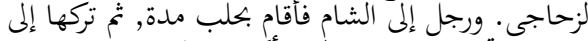

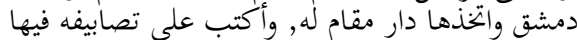

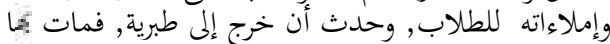

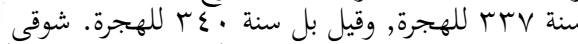

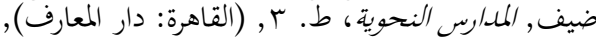

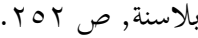

' و أبو الفتح عثمان بن جنى الموصلى, كان أبوه

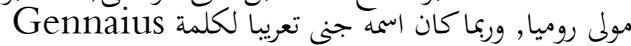

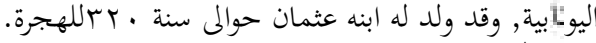

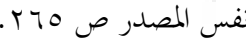


يكيل الى إكراه. مثلا في علم

الإعلال, "مد" أصله "مدد" إكراه

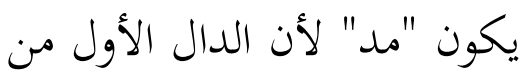

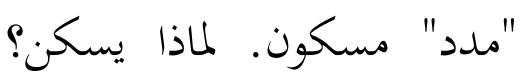

لأنه من شرط الإدغام. ثم الدال

الأول يدغم الى الدال الثان.

لماذا يدغم؟ لأن الدال الثاني

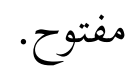

إذا كان تأثير المنطق على

النحو معروفا منذ قرن الرابع

الهجرى فمذهب الذى يرد على

تأثير ظهره مبكرا فن القرن الرابع لمدي

الهجرى الى غايته في القرن

السادس الهجرى. ينقسم

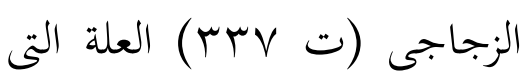

تطور في النحو الى ثلاثة أقسام:

العلة التعليمية, العلة القياسية,

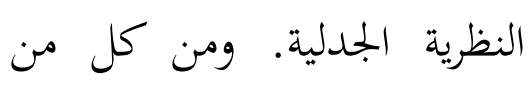

الثلاثة القسم الأول (العلة
التصميم منذ القرن الثان الهجرى

من عصر الخليل ابن احمد وامام

سيبويه الى الآن. وسبب ذلك أن أن إند

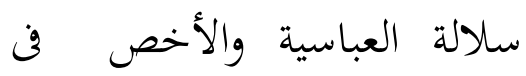

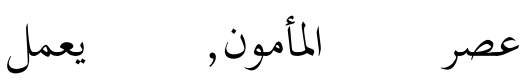

الإستكشاف على تأليفات

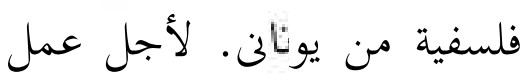

المأمون فلسفة يونانى(والخصوص يونات لاجل عمل

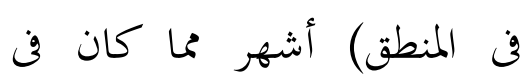

حلقه أهل العلم والمعرفة وله

التأثيرات على تصميم أيساسى

في العلوم الأخرى منها النحو.

التصميم في النحاة الذى النى

يتأثر بالمنطق يسبب النحو مليء

بالسبب والعلة, مثلا ما السبب الذباء

الذى يضم هذا اللفظ؟لأنه رفع.

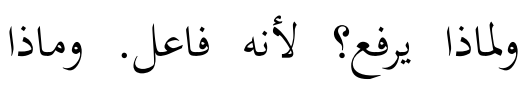

يرفع الفاعل؟ فعل, لأن لكل

المسبب السبب(العامل).

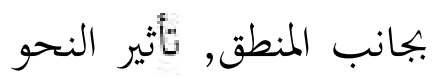

بتصميم العلة والقياس في الفقه 
لأن البابين قد يتخرج من تعليم<smiles>[AlH2][AsH2]=[VH2]</smiles>

جهد ابن مضاء فن الرد

على النحاة بكل جهده بتغيير

النحو القديم على سبيل

التصميم يقوده النظرية العامل

كما تقدم امام سيبويه. كما

يقول " وقصدي من هذا

الكتاب أن أحذف من النحو ما

يستغنى النحو عنه, ,انبه على ما أجععوا على الخطأ فيه"|' . تغيير

الإعراب عند ابن جنى ليس

لعامل لفظي او معنوي بل للمتكلم.

بوجه النظر على العامل فن

النحو عند ابن مضاء هو النظرية

الخيالية, وذلك لايوجد في الواقع

ويريد ابن مضاء في النحو الذى

ينشأ في الواقع الظاهر ليس بجعل

التأويل غير مهم. رد ابن مضاء
العليمية) يفيد لمعرفة اللغة

العربية

العلة التعليمة كما يقول

الزجاجى هى المسبب الأول من

تغيير الإعراب, مثلا اعرب

المفعول نصبا بل بحث له ما له

الذى ينصب المفعول وإلى العلة

فيما بعده. العلة المتوالية سميت

بالعلة الثانية, والثلاثة إلى أخرها.

وكان يرد البن مضاء على العلة

الثانية, الثلاثة إلى أخرها في

النحو. اللغة العربية ابل

بدراستها إكتفاء بالعلة الأولى.

جعلت العلة الثانية والثالثة فن

النحو ضخما وصعبا. ابن مضاء

من بعض النحاة الذى لا يوافق

بباب الإشتغال والتنزع في النحو

http://zamzamafandi.blogspot.com/200 8/06/pembaharuan-ilmu-nahwukajian.html. dikutip 2 Oktober 2010. 
وقد انصب نقده على

مارآه فسادا في نظرية العامل التى

دفعت النحاة الى مأفاضوا فيع

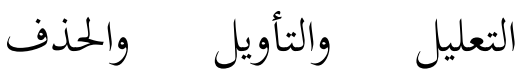

والتقدير , وكان فعله هذا أقرب

الى الوصفية التى تبتعد عن لتعن

استخدام التعليلات المنطقية,

وماترتب على نظرية العامل من

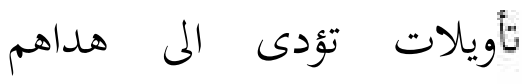

العلاقة بيب المبنى والمعنى.

ج. ابراهيم مصطفى واحياء النحو

1 ـ موجز من حياة ابراهيم مصطفى و

الظروف العامة قبل تصنيف كتابه

احياء النحو

أ) موجز من مياة ابراهيم

مصطفى

ابراهيم مصطفى مو

التمثيليّ من النحاة المعاصرة فن مئم

تجديد النحوى. وهو معلّم بكلّية

الآداب بجامعة فؤاد الأول (والآن

تكون بجامعة الأزهر بمدينة
على نظرية العامل يقوده الم

مذهب النحو الأكبر فن القرن السادس ولو كان ارتفاع صوته

صغير.

اذا, من الممكن أن بحديد

النحو الذى تقدم ابن مضاء

بصوت مرتفع هو خيبة ظنه على

نظرية النحو اعتبره مفكوك من

الواقع, ولول كان انقياده منطلق

من مذهبه الفقهى الظاهري.

وهو قاضى القضاة في عصر أمير

يوسف بن عبد المؤمن سلطان

الموحدين الثالث (أندلوسي)

مشهور بتطبيق مذهب الظاهرى

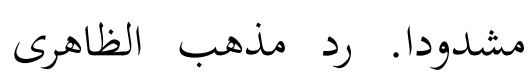

على التأويل. أما نظرية العامل في النحو مليئ بالتأويل, ولذلك هناك تحليل يريد ابن مضاء يقوم

بمذهب الظاهري في النحو 'ب . 
يتصل بينهما في الأزهر. ـ وإذا دروس الجامعة تفتح لحوارهما آفاقا طريفة, هما يتلذ بكما و يستحبهما، فيمضيا في الحوار وينسا لهما كل شىء وكل إنسان. فذهب ابراهيم مصطفى الى

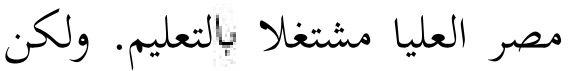
أرد الله أن يجمعهما بعد افتراق مرة أخرى فإذا هما في الجامعة المصرية الجديدة ويعمل معا بالتعليم. وحين لايستطيها بحاول الأيام أن يفرقا، خرج طه حسين من الجامعة ولزم دارى حينا، وشغل بالسياسة. وقال طه حسين أنه يتصور إحياء النحو على وجهين : أن يقربه النحويون من العقل

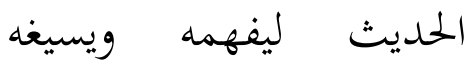
ويتمثله، ويجرى عليه تفكيره

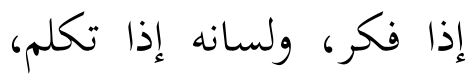
وقلمه إذاكتب.

r أن أن يشيع فيه هذه القوة التى تحبب إلى النفوس درسه
القاهرة). وفن سنة ألف وتسع مائة ست وثلاثين حصل ابراهيم

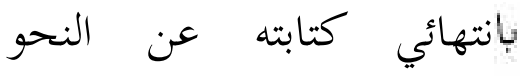
ويسمى احياء النحو. وكان طه حسين قد يتكلّم فن مقدمته لكتاب احياء النحو، أنه يعرف

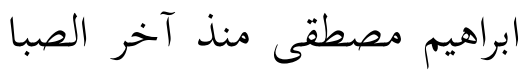

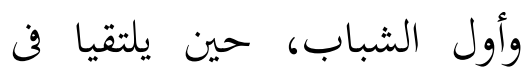
حلقات الدرس فن الأزهر الشريف فسمعا لشيوخهما، ثم يلتقيا مه طه حسين بعد لئل

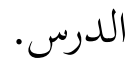

وعندما افترقا ابرهيم مصطفى و طه حسين، فذهب ابراهيم مصطفى إلى دار العلوم ثم أبى الله

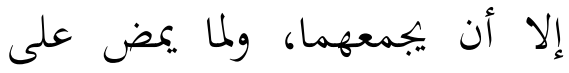
فراقهما إلا أقل الوقت وأقصره، فإذا يلتقيا فن غرفات الجامعة المصرية القديمة، وسمعا للأساتذة المحدثين من المصريين والأجانب. ثم لا يكاد يخرجا من غرفات الدرس، حتى 
وقال ابراهيم مصطفى فن مقدمته

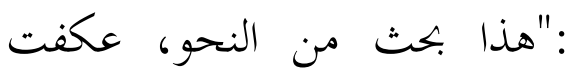

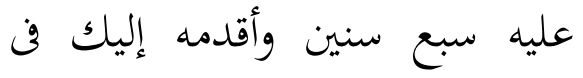
صفحات". للكتاب اثنتاعشر قسما: والقسم الأول هو حدالنحو كما رسمه النحاة، وكان ابراهيم مصطفى قد يتكلم عن غاية النحو

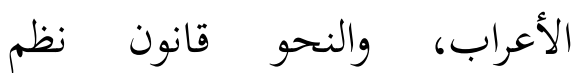
الكلام، وإهمال النحاة طرق الإثبات والنفى والتأكيد والثوقيف والتقديم والتأخير وغيرها من صور الكلام. والقسم الثانى هو وجهات البحث النحوى، وكان ابراهيم مصطفى قد يتكلم عن عناية العرب

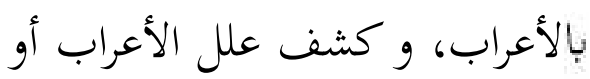

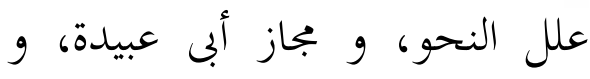
نظم عيد القاهر الجرجاني. والقسم الثالث هو أصل الإعراب، وكان ابراهيم مصطفى قد يتكلم عن أصل الاعراب وكان

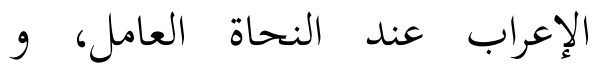
فلسفة العامل، و منشأ هذه
ومناقشة مشائله، والجدال فن أصوله وفروعه، وتضطرب الناس إلى أن يعنوابه بعد أن يهملوه، ويخوضوا فيه بعد أن يعرضوا عنه. اتصل ابراهيم مصطفى بدراسة النحو في كل معاهد التى يدرس فيها بمصر، وكان اتصالا طويلا وثيقا؛ و رأى عارضة واحدة، لايكاد يحتص بهما معهدون معهد، ولا تمتاز بهما دراسة عن دراسة. ب)الختويات لكتاب احياء النحو إحياء النحو هو كتاب ألّهه إبراهيم مصطفى عن النحو. وقد الئد

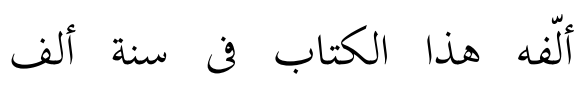
وتسع مائة ستّ وثلاين ملادية. وبعد سنة، في سنة الف وتسع مائة ونائة سبع وثلاين ملادية طبعه ونشره

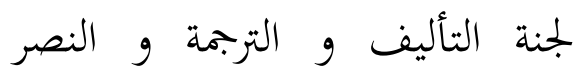
بالقاهرة هذاالكتاب، وكان طه لونان حسين بك قد تقديم هذاالكتاب. 
والقسم الثامن هو الأصل فن

المبنى أن يسكنا، وكان ابراهيم

مصطفى قد يتكلم عن إحصاء حروف المعان. والقسم التاسع هو العلامات الفرعية للإعراب، وكان ابراهيم مصطفى قد يتكلم عن

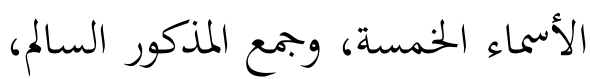
و مالايتصرف.

والقسم العاشر هو التوابع، وكان ابراهيم مصطفى قد يتكلم عن

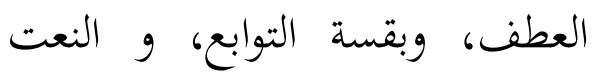
السبىى، و الخبر. والقسم الحادى ولئه عشر هو تكملة البحث فن مواضع

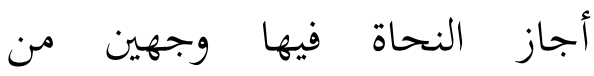
الإعراب، وكان ابراهيم مصطفى قد يتكلم عن باب (لا) ، و استعمال (لا) فن الكتاب الكريم، و استعمالها

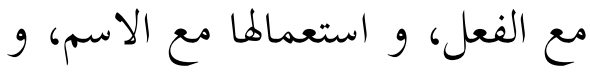
خلاصة القول فن (لا) وإعراب اسمها، و باب (ظن)، و باب الاشتغال، و المفعول معه.
الفلسفة، و نقد مذهب النحاة في العامل، و رأى المستشرقين في أصل الإعراب، ونقد مذهبهم. والقسم الرابع هو معان الإعراب.

والقسم الخامس هو الضمة علم الإعراب

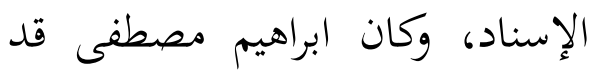
يتكلم عن الميتدأ والفاعل و نائب الفاعل، و المنادى، و اسم ان. والقسم السادس هو الكسرة علم الإضافة، وكان ابراهيم مصطفى قد يتكلم عن معان الإضافة. والقسم السابع هو الفتحة ليست علامة

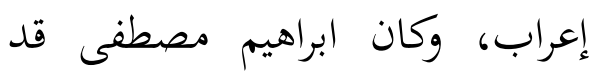

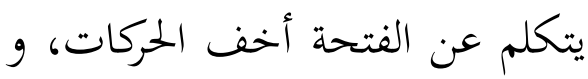

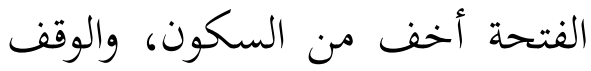
بالنقل يشهد بأن الفتحة ليست علم الفحرد

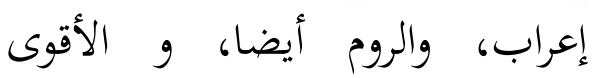
والاصراف وشهادتما بأن الفتحة ليست علم إعراب، و من كلام النحاة مايدل على أن الفتحة ليست بعلم إعراب. 
الكلمة، بل على خاصة من خواصه،

$$
\text { وهى الإعراب والبناء". }
$$

وبهذا التحديد قال ابراهيم

مصطفى تضييق لدائرة البحث النحوى، وتقصير لمداه، لأنّ النحو للحي

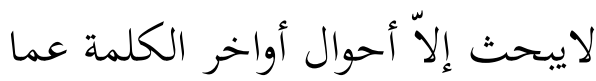

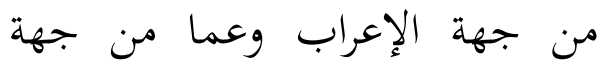
البناء. من هذا أتي ابراهيم مصطفى الإعل هن بتعريف النحو وقال : " النحو هو النين الناء قانون تأليف الكلام، وبيان لكل مايجب أن تكون عليه الكلمة فن الجملة, والجملة مع الجمل، حتى الحيه تتسق العبارة ويككن أن تؤدى

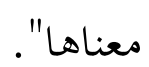

وقال ابراهيم مصطفى فالنحاة حين قصروا النحو على أواخر الكلمات وعلى تعرف أحكامها قدضيقوا من حدود الواسعة، وسلكوا به طريقا منحرفة، إلى غاية قاصرة، وضيعوا كثيرا من أحكام نظم الكلام

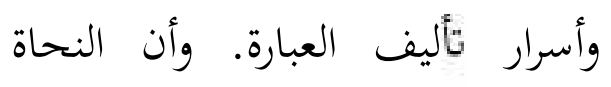

والقسم الثاني عشر هو الصرف، وكان ابراهيم مصطفى قد

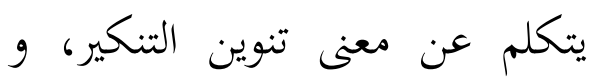

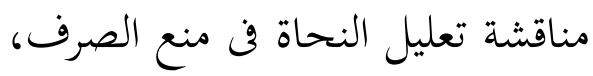
و مناقشة الأسباب التى وضعوها لمنع

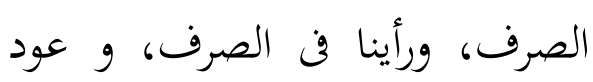
إلى مناقشة علل النحاة في منع العلم من الصرف، و مناقشة العلة التى

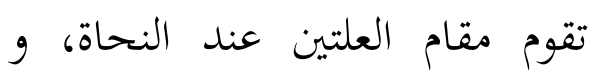

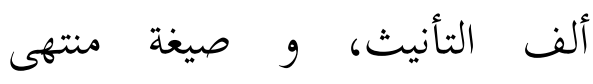
الجموع. د. التجديد لإبراهيم في مفهوم النحو العرى ( ) النحو العربى قبل أن يقدم بالترجمة لإبراهيم مصطفى عن النحو حيث أنه يرفض على النحاة التقليدية فن تعريف علم النح النه يرصن

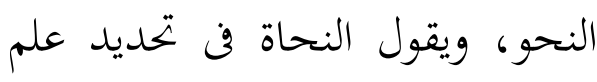
النحوس-" إنه علم يعرف به أحوال

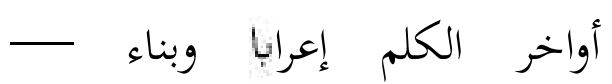
فيقصرون بحثه على الحرف الأخير من 
الأحوال المختلفة اللّفظ

من رفع أونصب من غير

فطنة لما يتبع هذه الأوجه

من أثر فن المعنى. يجيزون

في الكلام وجهين أو أو المني

أكثر من أوجه الإعراب،

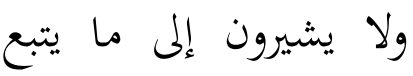

كل وجه من أثر فن رسم

المعنى وتصويره. و وبهذا

يشتد جدلهم ويطول

احتجاجهم، ثم لاينتهون

إلى كلمة فاصلة.

هـ. نقد ابراهيم مصطفى فن العامل

لقد اضطروا في سبيل تسنوية

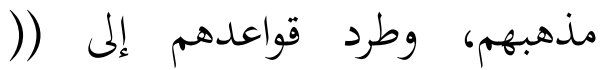

التقدير )) وأكثروا منه، يبحثون عن

العامل فن الجملة فلا يجدونه فيمدهم

التقدير بما أرادوا. ومن أمثلة ما ما فلها فيما

يقدرون :زيدا رأيته: يقولون هو -

رأيت زيدا رأيته.
حين قصروا النحو على البحث فن

أواخر الكلام قد أخطأوا إلى العربية البحت

من وجهين :

أ) إثم حين حددوا النحو

وضيقوا بحثه، حرموا

أنفسهم وحرمونا إذ

اتبعناهم من الإطلاع

على كثير من أسرار

العربية وأساليبها المتنوعة، هن

ومقدرقا ف في التعبير؛

فبقيت هذه الأسرار

بجهولة، ولمز نزل نقرأ

العربية ونفظها ونرويها،

ونزعم أننا نفهمها ونخيط

بما فيها من إشارة، وما

لأساليبها من من إلالة،

والحق أنه يخفى علينا كثير

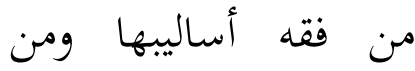

دقائق التصوير بكما.

ب)إنم رسموا للنحو طريقا

لفظية، فاهتموا ببيان 
والمقدّر فن الكلام نوعان : ويكون قد فهم من الكلام، ودلّ عليه سياق القول، فترى المحذوف جزءا من المعنى، كأنك نطقت به، وإنما تخففت بحذفه، وآثرت الإيجاز بتركه، وهذا أمر سائغ فن كل لغة، بل هو فن العربية أكثر لميلها إلى الإيجاز التخففت بحذف مايفهم. ولكن الإنا التقدير الذى نعيبه هو نظير ماقدمنا لك من الأمثلة : كلمات بتتلب لتصحح الإعراب، ولتكمل نظرية العنات العامل، ويسمى النحاة هذا النوع من

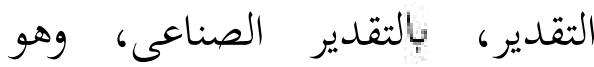
مايراد به تسوية صناعة الإعراب. فالبصريون يجعلون الرفع للمبتدأ هو الإبتداء، هو عامل معنوى.

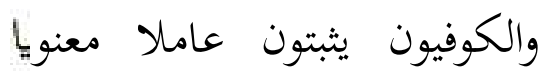
آخر يسمونه الخلاف، يجعلونه عامل النصب في الظرف إذا كان خبرا، نو زيد عندك، وفى الفعل المضارع بعد فاء السببية أو واو
) إن أحد من المشركين استجارك: -- إن استجارك أحد من المشركين استجارك. ) لو أنتم تملكون خزائن رحمة ربّ المثركين : - - لو تملكون تملكون خزائن رحمة ربّى. ) وأمّا ثمود فهديناهم :-- وأما رلما ثمود فهدينا هديناهم. ) إياك والأسد : -- أخذرك واحذر الأسد.

) ويقطع النعت في مثل : الحمدلله رب العالمين، فتنصب القيل كلمة رب، وترفع ؛ فيقدرون هو ربّ، أو أمدح ربّ. هذه الأمثلة لها نظائر كثيرة متعددة تملأ أبواب النحو، ولولا طول

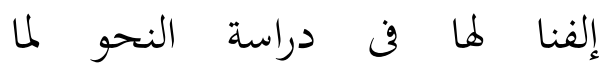
استسغناها ولرأيناها لغوا وعبثا، ولكن عليها بنى النحو، وأقيمت فصوله، إذا أقيمت على نظرية العامل. 
يأتى بحركة الضمة. على رغم من أربعة الأول يكون في النحو نقدر التحرة على حركة الكسرة و على حركة الفتحة.

وعلى أن العلامة الإضافة هى الكسرة، إذن الكسرة علم الإضافة. والكسرة- -كما قدمنا. سواء كانت هذه الإضافة بلا أداة، كمطر السماء، كمطر من السماء. ولا نجد

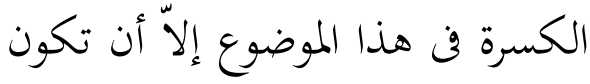
في اتباع كالنعت، أو فن المجاورة، وهى الدى ان تكون نوع من الإتباع.

الحاتمة

تاريخ النحو العرى قد مر بعدة

محاولات للإصلاح من منهجه، بغية تيسيره واستعابه من قبل الناشئة والدارسين، وهذه المحاولات لم تكن قريبة

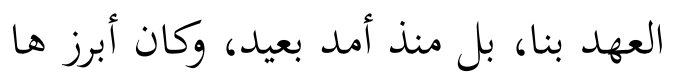

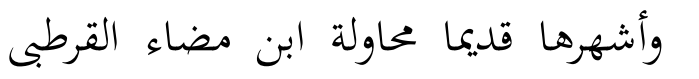

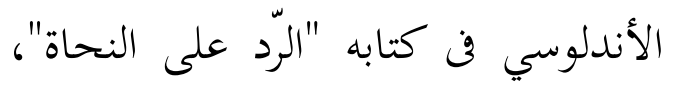

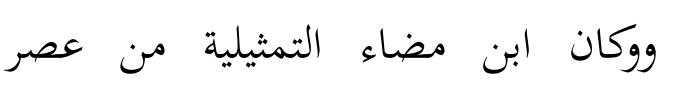

المعية، والأخفش يعد التبعية عاملا معنويا. أمّا في باب التمييز فقالوا : إن الاسم نصب عن تمام

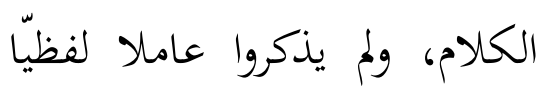

$$
\text { و ولا معنديا. }
$$

وإذا علمنا علامة الإعراب

الثلاثة : الفتحة، الكسرة، والضمّة

أتي إبراهيم مصطفى بأن الفتحة لا لا

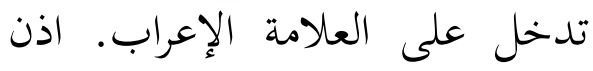
لإبراهيم مصطفى علامة الإعراب تنقسم إلى قسمين هو الضمة والكسرة, وكلاهما ليس بسبب العامل ولكن من المتكلم وحده. وقال إبراهيم مصطفى الأصل الأول أن الضمة واليما

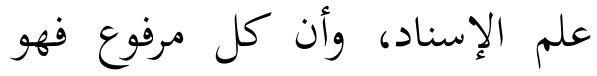
مسند إليه متحدث عنه. لذك، فرّق إبراهيم مصطفى على الباحث فن المبتدأ، والفاعل، و ونائب الفاعل، لئل واسم كان. وعند إبراهيم مصطفى كلّها تدلّ على النوع المسند إليه و وإنيم 
: "تقرؤه فلا بتحد في الكتاب أنك تنتزع

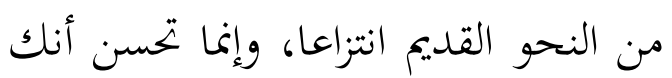
تمعن فيه إمعانا، وكأنك تقرأ كتب الأئمة المتقدمين من أعلام البصرة والكوفة

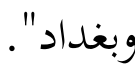

\section{المراجع}

أحمد، السيد الهانمى،1901 . القواعد

الأساسية اللغة العربية، بيروت :

$$
\text { دار الكتب العلمية. }
$$

حسان، تمام، 919 ا. الأصول : دراسة

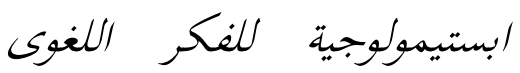

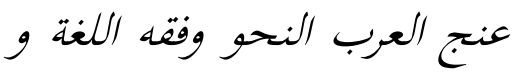

البلاغة، ريخ: الميئة المصرية

$$
\text { العامة. }
$$

خلدون، ابن،دون سنة. مقدمة /بن

خلدون، بيروت : دار الفكر.

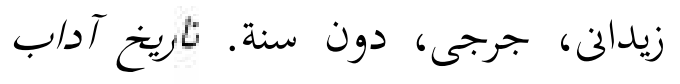

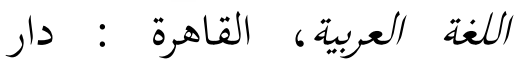

$$
\text { الهلال. }
$$

ضيف، شوقى، دون سنة الملدارس

النحوية، القاهرة : دارالمعارف.
التقليدية. وكان إبراهيم مصطفى هو رجل أى تمثيلي من عصر الحديث.

وقال ابراهيم مصطفى أن النحو هو " النحو هو قانون تأليف الكلام، وبيان لكل مايجب أن تكون عليه الكلمة في

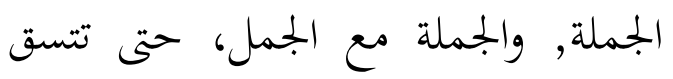
العبارة ويككن أن تؤدى معناها"، بهذا لهما التعريف على أنه ينقد في تحديد النحو

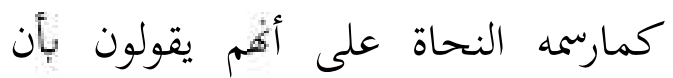
النحو هو " إنه علم يعرف به أحوال أواخر الكلم إعرابا وبناء - فيقصرون بحثه على الحرف الأخير من الكلمة، بل على إعلى وبناء خاصة من خواصه، وهى الإعراب والبناء". ينقد ابراهيم مصطفى بانتقاد الجارحى، نقد ابراهيم مصطفى بهذا

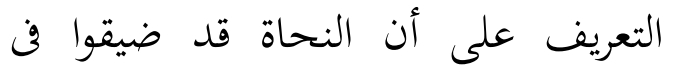
بحث علم النحو. ورغم دعوة ابراهيم مصطفى لإعادة النظر في درس العربية فإنه انتهى إلى الإبقاء على الجانب التعليمى وحلده،

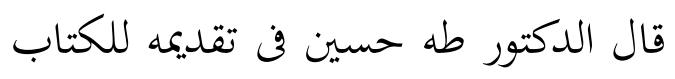


السيوطى، دون سنة. المزهر فى علوم اللغة

وأنواعها، القاهرة : دار الفكر

الشاطر، مُحَّمَ أحمد مُعَّة، دون سنة. الموجز

في نشأة النحو، القاهرة :

$$
\text { مكتبة كلية لازهر }
$$

الشايب، أحمد، ولو ا. أصول النقل

الأدبي، القاهرة : مكتبة النهضة

المصرية، الطبعة السابعة.

الطنطاوى، تُجََّ، نشأة النح، القاهرة :

$$
\text { دارالمعارف. }
$$

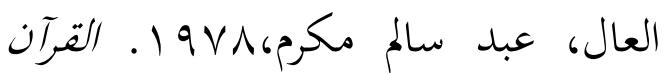
الكريم و وأثته في الدرسات

النحوية ، كويت : الجامة.

الكريمة، عناية، دون سنة. دور /بن مالك

في علم النحو العبر، مخطوطة

بككتبة الجامعة لاملامية

$$
\text { الحكومية. }
$$

Abraham, George Makdisi, 2005. Cita Humanisme Islam, Jakarta : Serambi

$$
\begin{aligned}
& \text { عيد، مُحَّة، 919 1. أصول النحو العربى } \\
& \text { في نظر النحاة ورآى ابن مضاء } \\
& \text { وضوء علم اللغة الحلديثة، القاهرة } \\
& \text { : عالم الكتب. } \\
& \text { فريهة، أنيس، ا919 1. نظريات في اللغة، } \\
& \text { بيروت : دار الكتاب اللبنان. } \\
& \text { مصطفى، ابراهيم، } 9 \text { IVV. احياء النحو، } \\
& \text { القاهرة : لجنة التأليف والترجمة } \\
& \text { والنثر } \\
& \text { معلوف، لويس، ال919 ا ـ المنجل في اللغة } \\
& \text { والأعلام، بيوروت : دار المسق. } \\
& \text { منظوم، ابن، دون سنة. لسان العرب، } \\
& \text { مصر: الدار المصرية، للتأليف } \\
& \text { والترجمة. } \\
& \text { الدين، مي،1 ·. . r. آراء الدكتور شوقى } \\
& \text { ضيف حول تبحليل النحو في } \\
& \text { كتاب تجاديل النحو، يوكياكر"ا: } \\
& \text { مكتبة الجامعة سونان كاليجاكا }
\end{aligned}
$$

